\begin{abstract}
Iranica
Abstracta Iranica Revue bibliographique pour le domaine irano-aryen

Volume 34-35-36 | 2017

Comptes rendus des publications de 2011-2013
\end{abstract}

\title{
Ludwig Paul. A Grammar of Early Judaeo-Persian
}

\section{Agnes Korn}

\section{(2) OpenEdition}

\section{Journals}

Édition électronique

URL : http://journals.openedition.org/abstractairanica/42409

DOI : 10.4000/abstractairanica.42409

ISSN : 1961-960X

Éditeur :

CNRS (UMR 7528 Mondes iraniens et indiens), Éditions de l'IFRI

\section{Référence électronique}

Agnes Korn, « Ludwig Paul. A Grammar of Early Judaeo-Persian », Abstracta Iranica [En ligne], Volume 34-35-36 | 2017, document 6, mis en ligne le 30 juillet 2017, consulté le 02 octobre 2020. URL : http:// journals.openedition.org/abstractairanica/42409; DOI : https://doi.org/10.4000/abstractairanica. 42409

Ce document a été généré automatiquement le 2 octobre 2020.

Tous droits réservés 


\title{
Ludwig Paul. A Grammar of Early Judaeo-Persian
}

\author{
Agnes Korn
}

\section{RÉFÉRENCE}

Ludwig Paul. A Grammar of Early Judaeo-Persian. Wiesbaden, Reichert, 2013, 188 p. +2 planches [http://reichert-verlag.de/fachgebiete/sprachwissenschaft/

sprachwissenschaft_indogermanistik/

9783895009693_a_grammar_of_early_judaeo_persian-detail]

1 Ce volume, issu du mémoire d'habilitation de l'auteur, présente une grammaire du judéo-persan archaïque, c.-à-d. des sources persanes en écriture hébraïque de la moitié du VIIIè au XIIIè siècle. Par ses sources les plus anciennes, le judéo-persan fournit donc des données qui précèdent celles du persan de plus d'un siècle.

2 La plupart des sources proviennent du Caire, plus précisément de la genizah de la synagogue Ben Ezra, qui est le dépôt rituel de manuscrits dans lesquels figure le nom de Dieu, raison pour laquelle on ne peut pas les jeter quand on n'en a plus besoin. Comme le nom de Dieu figure déjà dans un texte quand on fait par exemple mention d'une personne X fils ou fille du feu Y (ici suit une formule traditionnelle), la vaste majorité des documents à caractère légal ainsi que des lettres etc. entrent dans le cadre de ceux à déposer dans une genizah. Cette tradition a donc sauvegardé des sources originales qui, le climat sec aidant, se sont préservées jusqu'à nos jours. On dispose aussi de manuscrits et inscriptions trouvés au long de la Sérinde.

3 Évidemment, le judéo-persan étant défini en tant que tel par l'usage de l'écriture hébraïque, n'est pas un dialecte homogène; les manuscrits proviennent de régions diverses et s'étendent sur plusieurs siècles. La période du judéo-persan archaïque est suivie du judéo-persan moderne (XIIIè-XXè siècles).

4 Ceci dit, le judéo-persan archaïque se distingue du persan musulman par une série de traits dont quelques-uns le rapprochent au moyen perse, par ex. le thème du passé du 
verbe «faire » kird vis-à-vis au persan kard. Le judéo-persan archaïque complète ainsi nos connaissances sur le développement et la dialectologie du persan.

5 L'A. a structuré sa grammaire de façon claire et prévisible : l'introduction expose la description des textes et l'histoire de leur recherche ainsi que la bibliographie et des remarques d'ordre technique; elle est suivie d'un chapitre sur la phonologie (notons que l'on trouve dans certains textes des vocalisations). La morphologie occupe le centre de l'ouvrage (pp. 63-152). S'y ajoute un chapitre sur la syntaxe (la phrase nominale montre une variation importance de marquage et non-marquage de l'ezāfe; l'ordre des mots dans la phrase simple semble être un peu plus régulier qu'en persan; le subordinateur est soit $k i$, soit $k u$ ). L'appendice présente une table de matières détaillée très utile, un index de mots et des termes discutés et deux planches avec des images des caractères et ligatures de forme particulière.

6 Cette grammaire d'une forme du persan particulièrement archaïque est d'une grande importance pour l'étude de l'histoire du persan et ses dialectes.

\section{AUTEURS}

\section{AGNES KORN}

CNRS, Mondes iranien et indien 